\title{
The development of visual-motor search and the use of redundant information
}

\author{
ANNE D. PICK and MARSHA G. UNZE \\ University of Minnesota, Minneapolis, Minnesota 55455
}

\begin{abstract}
The purposes of these studies were to assess the generality of previously observed developmental trends in visual attention and to identify age changes in children's use of redundant information in a visual-motor search task. In the first study, children and adults searched for and retrieved target letters in collections of colored plastic letters. The collections varied in the degree to which the colors of the targets were correlated with their shapes. Search times were faster in redundant conditions than in nonredundant conditions, and the search times increased further in speed over trials in most redundant conditions. Older subjects increased in efficiency of search earlier in the task than younger subjects did. In the second study, children of the three youngest age groups searched for target letters in three redundant conditions. There were age differences in how the children used redundancy to aid visual search. The youngest children used it best if they were told of its presence, whereas older children used it equally well if they discovered it themselves.
\end{abstract}

A well documented developmental trend in visual perception is that referred to by Gibson (1969; Gibson \& Levin, 1975, pp. 41-42) as the "optimization of attention." There are age differences in children's abilities to select and use only relevant information (Pick, Christy, \& Frankel, 1972; Pick \& Frankel, 1973), to shift quickly from selecting one type of relevant information to another (Pick \& Frankel, 1974), and to direct and control their own visual searches (Miller, 1973; Nodine \& Steuerle, 1973). In short, children achieve progressively greater efficiency and flexibility in regulating attention (Pick, Frankel, \& Hess, 1975).

In most of the studies from which these developmental changes in attention have been inferred, children performed search or detection tasks with twodimensional items under conditions of brief exposure. However, much visual attention ordinarily occurs in settings in which there is sustained coordinated eyehand search through three-dimensional items that do not disappear from view. One purpose of the present

This research was supported by grants from the National Institute of Child Health and Human Development to the University of Minnesota Institute of Child Development (HD 05027) and Center for Research in Human Learning (HD 01136), and by a grant from the National Science Foundation, also to the Center (GB-17590). The authors are especially grateful to the children who participated in these studies from the Children's Corner, St. Paul, Minnesota; the Jewish Community Center Camp Centerland (Susan E. Muenzer, Director), St. Paul, Minnesota; St. Paul's Childhood Center (Shirley Smith, Director), St. Paul, Minnesota; and Hobbit Holes I and III, Brimhall Elementary School (Burdell Nelson, Principal), Roseville, Minnesota. We also appreciate the assistance of Marsha Olsen and Douglas Bolin in data collection, and of Sharon Modorski in data analysis. Requests for reprints should be sent to Anne D. Pick, Institute of Child Development, 51 East River Road, University of Minnesota, Minneapolis, Minnesota 55455. studies was to assess the generality of previously observed trends in the development of attention by asking children and adults to perform visual-motor search tasks with three-dimensional, manipulable objects that remain visible continuously.

A second purpose of the present studies was to investigate age relations in children's discovery and use of redundant information in a search task. In many search tasks in which we engage ordinarily, there is redundant information about the object of the search. The familiar book we search for on a shelf has a title, an author, a style of print, a color, and a size relative to other books. In some visual search tasks, knowledge of redundant information facilitates adults' search times (Smith, 1962). The ability to use such information improves with age; it is not routinely used effectively by very young children (Gibson \& Levin, 1975, pp. 25 26; Keeney, Jenkins, \& Jenkins, 1969), even when they are informed of its presence and specifically directed to use it (Day, 1978). The fact that older children and adults complete search tasks more efficiently may be due not only to their search patterns being more systematic than those of younger children (Mackworth \& Bruner, 1970; Vurpillot, 1968), but also to their greater skill in making use of redundant information about the object of their search.

\section{STUDY 1}

\footnotetext{
Method

Subjects. A total of 200 persons participated as subjects in the study: 50 preschool children [ 31 girls, 19 boys; mean chronological age $(\mathrm{CA})=4$ years 11 months], 50 first- and second-graders ( 27 girls, 23 boys; mean $C A=7$ years 8 months), 50 fifth- and sixth-graders ( 29 girls, 21 boys; mean CA $=11$ years 10 months), and 50 university undergraduates (32 women,
} 
18 men). Ten subjects from each age group were assigned unsystematically to each search condition.

Materials. The subjects' task was to search through collections of colored plastic letters for specified target letters and to remove all the target letters from the collections. The letters were three-dimensional (about $3.7 \mathrm{~cm}$ high $\times$ 2.2-3.6 cm wide $\mathrm{x}$ $.7 \mathrm{~cm}$ deep) and uppercase. There were eight colors represented in the collections, and all letters of the alphabet except I and L. These were excluded because they were easily confused with numbers.

In order to maintain motivation throughout the task, and to avoid fatiguing the younger participants, subjects of different ages searched through different-sized collections. In all collections, $15 \%$ of the letters were targets. There were 58 letters in the preschool children's collections, 78 in the first- and second-graders' collections, 98 in the fifth- and sixth-graders' collections, and 118 in the adults' collections. Three letters were designated as targets for each collection. There was always more than one instance of each target letter, and obviously, the number of instances varied with the size of the collection.

The collections were presented to subjects unorganized in a cardboard search box that was open and was about $25 \mathrm{~cm}$ long, $17.5 \mathrm{~cm}$ wide, and $4.5 \mathrm{~cm}$ deep. The target letters for each search were traced in black on a card, $15.2 \times 10.2 \mathrm{~cm}$, that remained visible throughout the task.

There were five conditions of the search task, and the conditions differed in the degree to which color was correlated with the particular letters designated as targets. In the nonredundant single-color condition, there was no color variation at all. The collection and target letters were all the same color. In the nonredundant multicolor condition, the target letters varied in color unsystematically, as did the other letters in the collection. Thus, in these two conditions, color was unrelated to the targets.

In the partially redundant condition, all of the instances of one target were the same color, although different targets were represented by different colors, and other letters in the collection occurred in those colors, as well. For example, if letters $A, G$, and $M$ were designated target letters, all of the As would be one color (e.g., red), all of the Gs would be another color (e.g., blue), all of the Ms would be a third color (e.g., green), and there would be other red, blue, and green letters in the collection. Thus, color and target letter were partially redundant in this condition.

In the redundant condition, all instances of all three target letters were the same color, and they were the only letters of that color in the collection. The redundant informed condition was identical to the redundant condition except that in the former, the subjects were told at the beginning of the task about the redundancy of colors and targets. Since there was more shape variation than color variation in the collections, it would be efficient to search for items of a particular color instead of (or in addition to) items of a particular shape when the two are correlated.

Procedure. The preschool and elementary school children were tested individually in small rooms near their classrooms. The adults were tested individually in a small experimental room located in a university building. Consent for participation was obtained from all subjects, and from the parents of the children.

The child and experimenter were seated side by side at a small table. The experimenter explained that the child was going to play a game with some letters, that a lot of letters would be put in the search box, and that the child would look for certain letters and take those out of the box. The experimenter showed the child a card with three letters on it and explained that the child should find all the letters that matched the ones on the card. The card remained in view throughout the task. The experimenter also explained that there were several target letters, so the child should look for a few of each one, and the experimenter would say when all the targets had been found. The child was shown a stopwatch and told that the experimenter would use it to keep track of the time, so the child should find and remove all the targets as quickly as possible. An additional instruction given only to subjects in the redundant informed condition was that all of the target letters were of one color, and the particular color was identified. Then the card designating the first three target letters was shown, and the child searched through the collection for all the instances of those letters. The experimenter encouraged the child throughout the search, and when the child had found all of the target letters, the trial was concluded. The experimenter praised the child for "being a good searcher" and then presented the card designating the three target letters for the next trial.

Each child completed six trials in the assigned condition. In the conditions in which there was some redundancy of colors with target letters, the particular colors correlated with the targets varied across trials. For each trial the experimenter recorded the child's search time, the types of search strategies used, and, where possible, the order in which the targets were found. The procedure for adults was exactly the same as for children except that the instructions, encouragement, and praise were appropriate for their age group.

\section{Results}

An analysis of variance with two between-subjects factors (grade and condition) and one within-subjects factor (trials) was computed for the subjects' search times, and student Newman-Keuls tests were used to make all appropriate group comparisons. (All $\mathrm{p}$ values $<.01$ unless otherwise specified.) As expected, the effect of grade was significant $[F(3,180)=46.08]$; the preschool children's search times (mean $=125.9 \mathrm{sec}$ ) were slower than those of the first- and second-graders (mean $=94.6 \mathrm{sec}$ ), which, in turn, were slower than those of the fifth- and sixth-graders (mean $=77.5 \mathrm{sec}$ ). The adults' search times (mean $=68.0 \mathrm{sec}$ ) were not different, statistically, from those of the oldest group of children.

The effect of condition was also significant $[F(4,180)=145.47]$. Search times in the redundant conditions (means $=94.7,52.6$, and $29.3 \mathrm{sec}$ for partially redundant, redundant, and redundant informed conditions, respectively) were all statistically different from each other, and they were all faster than the search times for the nonredundant conditions (means $=142.9$ and $138.1 \mathrm{sec}$ for single-color and multicolor conditions, respectively).

The other main effect, trials, was also significant $[F(5,900)=26.38]$. The search times for the first two trials (means $=104.7$ and $103.6 \mathrm{sec}$ for Trials 1 and 2, respectively) were not statistically different from each other, and both were slower than the search times for the third trial (mean $=95.0 \mathrm{sec}$ ), which, in turn, was slower than the search times for the last three trials (means $=76.8,83.8$, and 85.1 sec for Trials 4, 5, and 6, respectively). Search times for the last three trials did not differ from each other.

Although the Grade by Condition interaction did not reach an acceptable level of statistical significance $(.05<\mathrm{p}<.10)$ for group comparisons, there were 
apparent age-related effects in the two most redundant conditions. The overall differences between search times in the two conditions were much greater for younger children than for older children and adults (mean difference $=50.0,24.1,8.7$, and $10.3 \mathrm{sec}$ for the preschool, first- and second-grade, fifth-and sixth-grade, and adult groups, respectively).

The Grade by Trial interaction was significant $[F(15,900)=2.20]$. The preschool children's search times in the first three trials were slower than their search times in later trials. The older groups' Trial 1 search times were slower than their search times for later trials.

The Condition by Trial interaction was also significant $[F(20,900)=2.70]$. The subjects' search times in the nonredundant single-color condition and in the redundant informed condition did not change significantly over trials, whereas there were significant decreases in search times across trials for the other three conditions.

\section{Discussion}

The general developmental trend toward progressively more efficient attending is evident in these visual-motor search tasks in which the older groups' search times decreased with practice earlier in the tasks than did those of the younger children. The effects of the different conditions on search times were striking: Considerably more than twice as much time was required to complete a search in the nonredundant conditions than in some of the redundant conditions. In two conditions, there was not even any decrease in search times over trials. One was the redundant informed condition, which subjects completed very quickly from the start, and the other was the nonredundant single-color condition, in which there was no information available to use for searching more efficiently and completing the trials more quickly. When redundancy was present in the task, it facilitated the subjects' search times right from the start, and the presence of more redundancy was reflected in faster search times for subjects of all ages. Most subjects, including the youngest children, made comments about the redundancy, particularly in the redundant condition, and acted as though they were indeed taking advantage of it and seeking targets of a specific color.

Although not significant statistically, the pattern of search times suggested some developmental differences in the use of the available redundant information in the two most redundant conditions. Consequently, the second study was conducted in order to assess the reliability of this pattern, in which older groups searched as quickly when they discovered the redundancy as when they were told about it, whereas younger children did not take as much advantage of the redundancy if they discovered it for themselves.

\section{STUDY 2}

\section{Method}

Subjects. There were 80 subjects: 30 preschool children ( 19 boys, 11 girls; mean $\mathrm{CA}=4$ years 4 months), 30 first- and second-graders ( 13 boys, 17 girls; mean $\mathrm{CA}=6$ years 11 months), and 20 university undergraduates ( 9 men, 11 women).

Materials and Procedure. The materials, task, and sizes of the collections were the same as for the previous study. There were three conditions in the present study. Two were the redundant and redundant informed conditions of the previous study. In the third, the maximum redundant condition, all of the target letters were the same color, they were the only letters of that color in the collection, and the particular color (red) remained constant across trials. Thus, in the third condition, there was even more redundancy of color and target letters than had previously been provided.

Ten subjects at each of the two younger ages were assigned unsystematically to each of the three conditions. Ten adults were assigned unsystematically to each of the two conditions from the previous study. The new redundant condition was not conducted with adults, since, in the previous study, adults searched as quickly in the redundant condition as they did in the redundant informed condition.

The procedure was exactly the same as for the first study except that there were five trials of each condition instead of six.

\section{Results}

Since the new condition was not conducted with adults, two overlapping analyses were computed on the subjects' search times. The first was an analysis of variance for all three age groups for the two conditions in which subjects of all ages participated. The purpose of this analysis was to assess the replicability of the pattern observed in the previous study. The second analysis of variance was computed for the two groups of children for all three conditions in order to assess the relative effects of the new condition of maximum redundancy. For both analyses there were two betweensubjects variables (grade and condition), and one withinsubjects variable (trials). Student Newman-Keuls tests were again used for all appropriate group comparisons (all ps<.01).

All three main effects were significant in the first analysis: grade $[\mathrm{F}(2,54)=49.93]$, condition $[F(1,54)=41.90]$, and trials $[F(4,216)=10.99]$. The adults' (mean $=27.2 \mathrm{sec}$ ) and the first- and secondgraders' (mean $=36.6 \mathrm{sec}$ ) search times were faster than those of the preschoolers (mean $=86.6 \mathrm{sec}$ ), and search times in the first trials of a condition were slower than those for subsequent trials.

The Grade by Condition interaction was also significant $[F(2,54)=12.75]$. The preschoolers' search times in the uninformed condition (mean $=122.5 \mathrm{sec}$ ) were slower than all of the other groups' search times. Finally, the interaction of Grade by Condition by Trials was significant $[F(8,216)=1.98, p<.05]$. The pattern of differences reflected decreases in search time after the first trials of the redundant condition for the two oldest age groups, but not for the youngest children.

In the second analysis, also, the three main effects were significant: grade $[\mathrm{F}(1,54)=55.75]$, condition $[F(2,54)=14.17]$, and trials $[F(4,216)=12.89]$. The preschoolers' search times $($ mean $=88.3 \mathrm{sec})$ were slower than those of the older children (mean $=37.8 \mathrm{sec}$ ), and search times in the redundant informed condition (mean $=39.8 \mathrm{sec}$ ) were faster than those in the redundant condition (mean $=83.6 \mathrm{sec})$, with the search times in the maximum redundant condition (mean $=65.7 \mathrm{sec}$ ) intermediate between the other two. As before, search times for the first trial were slower than those for subsequent trials. 
Finally, the Grade by Condition interaction was significant $[\mathrm{F}(2,54)=5.51]$. The preschoolers' search times in the redundant informed condition (mean $=51.2 \mathrm{sec}$ ) were faster than their search times in the maximum redundant condition (mean $=91.2 \mathrm{sec}$ ), which, in turn, were faster than their search times in the redundant condition (mean $=122.5 \mathrm{sec}$ ). None of the differences among the older children's search times were statistically significant, nor were these search times different from the preschoolers' search times in the informed condition. As before, nearly all of the children in the uninformed conditions commented on the redundancy, indicating their awareness of its presence.

\section{Discussion}

The results confirmed the suggestion that there are agerelated differences in children's use of available redundant information to aid visual search. Preschoolers who were told about the correlation of color and targets took less than half as long to complete their searches as preschoolers performing an identical task who were not specifically told about the redundancy. That they used the redundancy, however, is reflected in the differences in their search times for the three tasks. The effect of informing the younger children may be to provide them with an explicit rule to follow, one that the older children can generate for themselves. Of course, the children were not told to follow a rule, but simply providing them the information may have given them an external impetus to follow a specific rule. The older children, who generally are better able to direct and control their attention, may do so, in part, by using information provided by the situation and discovered by themselves. The younger children benefited by being provided with maximum redundancy, but still not to the extent that they benefited by the experimenter's verbally noting the presence of a correlation between color and targets. In any case, the youngest children can use redundancy to search efficiently if its presence is pointed out, but they cannot take the same advantage of its presence to direct their own searches if they must discover the redundancy for themselves.

In general, the findings in these studies have confirmed inferences made from other kinds of tasks that children's visual attention evolves toward greater efficiency and flexibility. The changes that take place in children's abilities to use redundant information may be one means by which they become progressively better able to direct and regulate attention.

\section{REFERENCES}

DAY, M. C. Visual search by children: The effect of background variation and the use of visual cues. Journal of Experimental Child Psychology, 1978, 25, 1-16.

Gibson, E. J. Principles of perceptual learning and development. New York: Appleton-Century-Crofts, 1969.

Gibson, E. J., \& Levin, H. The psychology of reading. Cambridge, Mass: M.I.T. Press, 1975.

Keeney, T. J., Jenkins, J. R., \& Jenkins, J. J. Identification of absolute and relational properties in the three-stimulus (ABB) configuration. Child Development, 1969, 40, 1223-1231.

Mackworth, N. H., \& Bruner, J. S. How adults and children search and recognize pictures. Human Development, 1970, 13, 149-177.

Mille R, L. K. Developmental differences in the field of view during covert and overt search. Child Development, 1973, 44, 247-252.

Nodine, C. F., \& Steuerle, N. L. Development of perceptual and cognitive strategies for differentiating graphemes. Journal of Experimental Psychology, 1973, 97, 158-166.

Pick, A. D., Christy, M. D., \& Frankel, G. W. A developmental study of visual selective attention. Journal of Experimental Child Psychology, 1972, 14, 165-175.

Pick, A. D., \& Frankel, G. W. A study of strategies of visual attention in children. Developmental Psychology, 1973, 9, 348-357.

Pick, A. D., \& Frankel, G. W. A developmental study of strategies of visual selectivity. Child Development, 1974, 45, $1162-1165$.

Pick, A. D., Frankel, D. G., \& Hess, V. L. Children's attention: The development of selectivity. In E. M. Hetherington (Ed.), Review of child development research (Vol. 5). Chicago: University of Chicago, 1975.

Smith, S. L. Color coding and visual search. Journal of Experimental Psychology, 1962, 64, 434-440.

Vurpillot, E. The development of scanning strategies and their relation to visual differentiation. Journal of Experimental Child Psychology, 1968, 6, 632-650.

(Received for publication July 3, 1979.) 